\title{
E-GOVERNMENT EVALUATION: REFLECTIONS ON THREE ORGANISATIONAL CASE STUDIES
}

\author{
Stephen Jones \\ Conwy County Borough Council \\ Bodlondeb, Conwy, LL32 8DU, WALES, UK \\ steve.jones@.conwy.gov.uk \\ Zahir Irani and Amir Sharif \\ Department of Information Systems and Computing \\ Brunel University, Uxbridge, UB8 3PH, UK \\ zahir.irani@brunel.ac.uk
}

\begin{abstract}
The deployment of e-Government continues at a significant cost and pace in the worldwide public sector. An important area of research is that of the evaluation of e-Government. In this paper the authors report the findings from three interpretive in-depth organisational case studies that explore e-Government evaluation within UK public sector settings. The paper elicits insights to organisational and managerial aspects with the aim of improving knowledge and understanding of $e$ Government evaluation. The findings that are extrapolated from the analysis of the three case studies are classified and mapped onto a tentative e-Government evaluation framework and presented in terms lessons learnt. These aim to inform theory and improve $e$ Government evaluation practice. The paper concludes that e-Government evaluation is an under developed area and calls for senior executives to engage more with the eGovernment agenda and commission e-Government evaluation exercises to improve evaluation practice.
\end{abstract}

Key Words: e-Government Evaluation; UK Public Sector; Grounded Theory; Interpretive Case Studies.

\section{Introduction}

It is widely acknowledged that the emergence of Electronic Government (e-Government) has been due to the requirement to develop local and national government operational and process efficiencies, as well as providing accessibility to citizens and other involved stakeholders. Since many e-Government initiatives are seeking to radically change the semiotics of public sector and social groups, the implicit evaluation and understanding of such schemes presents a series of complex priorities and requirements, along both political as well as organisational lines. e-Government is seen by some to be IT/IS-led change and it is therefore important to carry out the evaluation of this phenomenon in order to determine the value and benefit derived.

Walsham [25] notes that many authors contend that a well-documented and formal approach to investment evaluation is required to understand the implications of any ICT investment on the organisation. Walsham [25] contends that formal mechanistic methods, based upon economic factors are the usual methods that are employed by organisations. Examples include Cost Benefit Analysis, Return on Investment and Payback. However, Bannister [2] argues that even when these formal methods are applied rigorously, their relevance in the public service domain is questionable, because economic measures, such as value and financial returns, are very difficult to define in the public sector. Serafeimidis and Smithson [18] argue that:

"ICT evaluation, based on narrow technical and accounting terms, has limited relevance to the role of ICT in today's organisations." [19], p. 94.

Many authors [3] [5], [26], [17], [9], [8] have noted that most public sector organisations do not undertake ICT evaluation. It unclear to what extent organisations evaluate e-Government but evidence suggests that mechanistic methods are unable to address e-Government evaluation. It follows therefore that there is an issue due to the apparent inability of public sector organisations to gauge the impact of e-Government.

It is against this backdrop that the paper seeks to increase the understanding and knowledge of e-Government evaluation in practice. The aim is to analyse findings from three in-depth interpretative case studies to map a tentative e-Government evaluation framework and extrapolate lessons learnt for e-Government evaluation. The framework and lessons will be grounded in the principles of knowledge gathering and organisational learning.

The paper begins with a brief literature review and presentation of the problem domain. This is followed by the research methodology. The paper continues with a brief summary of the empirical work in terms of three indepth case studies. This is followed by an analysis of the main themes of decision-making, evaluation, performance assessment and practitioner concerns which have been extrapolated from the three case studies. Arising from the analysis of these key themes, a tentative 
evaluation framework and lessons are elicited with the aim of informing theory and improving practice. eGovernment is still emerging and therefore it is argued that the findings are timely. The paper concludes that eGovernment evaluation is a under developed area. Furthermore the paper calls for senior executives to engage with the e-Government agenda and to commission e-Government evaluation. The research methodology and justification is now presented in the next section.

\section{Research Methodology}

An appropriate research methodology is required to research a particular area under study. Yin [27] has proposed several criteria for selecting a suitable research strategy. These factors should be considered in context with the research scenario. The authors aim to explore eGovernment evaluation, in context, to understand eGovernment evaluation practice and to elicit lessons for e-Government evaluation. The research methodology employed therefore, was the interpretive in-depth case study as described by Walsham [24], which was consistent with this aim.

Qualitative research methods, described by Walsham [24] were employed to undertake the research. These include informal, in-depth semi-structured interviews and participant observation. Grounded Theory as described by Glaser and Strauss [4] was used as the method for data collection and analysis of data from the interviews. Grounded Theory (GT) has a number of guidelines and procedures that help to structure and analyse data. These include seed categorising, open coding, axial coding, selective coding, theoretical sampling and constant comparison. GT is an inductive approach that generates categories and local empirical theoretical models, which are extrapolated from the social setting and tied to the data [24]. Conclusions or lessons can then be drawn from the theoretical models as part of the interpretive and inductive process.

Findings from a study of this type are local and largely indicative [24]. However, this should not be taken to imply that interpretive work is not generalizable, as local theory may be generally useful [24], which may then be used to inform other settings. Walsham [23] argues that the validity of the inferences drawn from one or more cases:

"depends on the plausibility and cogency of the logical reasoning used in describing the results from the cases, and in drawing conclusions from them" (Walsham [23], p. 15).

A full description and discussion of the GT process can be found in Urquhart [22]. Primary data was used to develop the findings presented in this paper. This data included interviews, observations, illustrative materials (e.g., current documentation, policies and procedures, eGovernment strategy and other publications that form part of all three case study organisational history), and archived documentation. Secondary data sources included internal reports, budget reports, and filed accounts that were later transcribed and formed the subsequent basis of qualitative content analysis [15].

One-to-one tape recorded interviews of approximately 1 hour were conducted. The interviewer carefully ensured that the interviewees were fully informed about the purpose of the interviews, and took steps to put the interviewees at ease so that a two-way, open communications climate existed. After every interview that was undertaken, notes were subsequently given to each person to check and resolve any discrepancies that may have arisen and to eliminate any interviewer bias. This approach to interviewing has proved successful in similar type of case-study research as reported by Irani et al. [10].

The authors initially undertook two case studies. The aim was not to compare the two cases to highlight differences, but to contrast the cases and to elicit key lessons by drawing on the findings. This research has been presented elsewhere Jones et. al, [11]. However, a third case study has subsequently been undertaken. This third case provided significant further exploration, understanding, insight, richness and lessons. The extrapolation of a tentative e-Government evaluation framework and lessons has been undertaken by contrasting and drawing on the analysis of the three cases. This concludes the research methodology section. In the following section the three case studies are briefly described.

\section{Case Studies}

The first case study concerns a UK unitary local authority, which provides a range of public services, including Education, Social Services and Highways. The population is 147,000 , the staffing establishment is 6,000 , the annual revenue budget is $£ 150 \mathrm{~m}$ and the annual IT revenue budget, including e-Government, is $£ 2.5 \mathrm{~m}$. Six senior e-Government stakeholders were interviewed as part of this case study. These were the Head of IT, IT Account Manager, IT Operations Manager, Assistant Director of Finance, a Senior Social Services Manager and Assistant Chief Executive.

The second case study concerns another UK unitary local authority, which provides a similar range of public services, as in case study one. It has a population of 129,000 , a staffing establishment of 7,000 , an overall annual revenue budget of $£ 157 \mathrm{~m}$, and an annual IT revenue budget, including e-Government, of $£ 2.2 \mathrm{~m}$. As in the first case, six senior ICT stakeholders were sought to 
enable the research to have sufficient depth and six agreed to be interviewed to contribute to the study. These were the Head of Information, Communications and Technology (ICT), ICT Operations Manager, the Deputy County Treasurer, a Senior Social Services Manager, a Senior Housing Manager and a Senior Finance Manager.

The third case study concerns another UK unitary local authority, which provides a similar range of public services, as in case studies one and two. It has a population of 110,000 , a staffing establishment of 6,500 , an overall annual revenue budget of $£ 168 \mathrm{~m}$, and an annual IT revenue budget, including e-Government, of $£ 2.8 \mathrm{~m}$. As in the previous cases, six senior e-Government stakeholders were interviewed to enable the research to have sufficient depth. These were the Head of Information, Communications and Technology (ICT), the ICT Services Manager, a Senior Education Manager, the e-Government Manager, a Senior Highways Manager and a Senior Finance Manager. The findings and outcomes from the studies are now presented in the following sections, in terms of analysis and learning.

\section{Research Findings}

Jones et al, [11] previously presented an analysis of the main emergent themes extrapolated from case study 1 and 2, however it is not the intention of this paper to rearticulate these findings in detail. Rather, the authors have built on these findings by analysing the third case study and presenting and contrasting the common themes in this paper. Four themes were extrapolated, these are decision-making, evaluation, performance assessment and practitioner concerns. It is important to again emphasise that any findings and lessons drawn from the three case studies are not generalizable, but may be generally useful [22]. The first key emergent theme is decision making and this is discussed in the next section.

\subsection{Theme One - Decision Making}

Decision-making with regard to e-Government issues in all three case study organisations was delegated and unsophisticated. Decisions were not made by senior executives but were delegated to middle managers. However, the decision to implement e-government was described as obvious and common sense. One interviewee stated 'It was something we had to do. Central Government had set out the agenda'. This resonates with the work of Bannister [2] who contends that decision-making in the public sector is often political and not always based upon economics. The delegated approach to decision making had led to a lack of eGovernment ownership at a senior executive level. For example, there was no strong senior executive sponsorship for e-Government in all three case study organisations. This led to a lack of senior corporate governance. However, the literature contends that senior management commitment is critical to e-Government success and furthermore that e-Government ownership is clearly understood in organisations.

There was resistance and lack of commitment from some internal users to exploit e-Government to improve the respective service area. This was illustrated by the lack of e-Government services in important areas such as Highways, Education and Social Service to varying degrees. Some senior staff described themselves as 'too busy' to prioritise and divert resources to e-Government and this resulted in a loss of opportunity to develop eGovernment to improve service delivery. To ensure effective e-Government governance and management it is important to decide and make clear who holds the different roles and responsibilities, and who is responsible for delivering the programme. These roles were different between authorities, as culture, organisational structures, programme and project management approaches varied. Some roles and responsibilities were shared and depended on the business case, the resources available, and the decisionmaking framework employed.

\subsection{Theme Two - Evaluation Methods}

None of the case studies were formally evaluating their eGovernment programmes. Mechanistic methods based upon economics were not used. The interviewees were generally aware of these methods but had not employed them. This was mainly due to them having limited credibility, due to their economic bias. They were viewed as not being appropriate for the public sector ICT projects and were not used to evaluate e-Government. The public sector is not motivated by financial gain and has to demonstrate economic probity and value for money to the citizen. The motivation for the public sector to deploy eGovernment is to transform and improve service delivery to the citizen. Therefore, as one interviewee commented 'costs savings were not a motivating factor'. However, that is not to say that the case studies did not wish to evaluate e-Government. Indeed, all three cases were of the view that e-Government evaluation was important, to able their organisations to assess e-Government implementations. A key issue therefore for the case studies is to select an appropriate e-Government evaluation model that can be useful. Irani and Love [9] have proposed a taxonomy of ICT evaluation approaches to assist in the choice of evaluation methods that include mechanistic and soft social and organisational aspects. It was recognised that soft aspects, especially citizen perspectives, were likely to be important to any eGovernment evaluation exercise. The three case study organisations were also coming under increasing pressure to adopt evaluation with the aim of benchmarking, understanding and improving e-Government deployment. The future challenge therefore is to understand the noncost value, benefits and impact of e-Government to each organisation and to employ appropriate evaluation 
approaches that can be helpful. The literature highlights that there is still widespread and continuing disagreement as to the factors and metrics to include in any formal ICT evaluation approach. However, e-Government evaluation must emphasis the soft aspects.

Responsibility for e-Government evaluation was unclear in all three organisations. Service managers and internal users had tacitly assumed that e-Government evaluation is the function of specialist ICT management. This important finding concurs with the view of Smithson and Hirschheim, [20], who note that ICT evaluation is usually assumed to be the responsibility of ICT management. ICT management were unaware that they had been deemed responsible for this aspect. Indeed, ICT management do not fully understand how e-Government impacts upon a service area or service delivery. It was recognised that responsibility for the evaluating the impact of e-Government should be clearly defined, articulated and understood. All three organisations had not give any priority to e-Government evaluation. Each organisations was more concerned with further developing e-Government and moving the e-Government agenda forward. However, once responsibility for eGovernment evaluation has been agreed, there is a requirement to prioritise this area.

In all three case study organisations, e-Government stakeholders were not concerned with e-Government economic metrics, detailed cost benefit analysis or mechanistic evaluation techniques. They were concerned with the successful introduction, operation and impact of e-Government. The aim of e-Government is to transform and improve public sector service delivery. Therefore, there was a need to gauge and understand what benefit the organisation and associated stakeholders obtain from e-Government implementations and to what extent eGovernment has been successful in practice. In the case studies, e-Government evaluation does not occur and internal and external stakeholder opinion is not formally canvassed. Therefore, it makes it difficult to judge the impact of e-Government and whether it has delivered significant service performance improvements. This needs to be addressed, especially as large costs are involved.

\subsection{Theme Three - Performance Assessment}

A key aspect of public sector organisations in the UK is the requirement for external performance assessments to be undertaken by independent, external government audit bodies. This audit assessment considers all aspects of organisational performance and awards the organisation a score of 1 to 4 , where 1 is poor and 4 is excellent. Clearly, an assessment of the organisations' eGovernment program is undertaken as part of the overall performance assessment exercise. However, there was no e-Government evaluation approach in any of the three case study organisations. Service managers and managers responsible for e-Government were aware of this aspect. One interviewee commented 'there is a need to deploy a framework to undertake some form of e-Government evaluation to satisfy the external audit bodies'. There is therefore, a need to adopt a framework or methodology to assess e-Government impact, not least to satisfy external audits. There is also the need to adopt evaluation metrics, in an attempt to benchmark and better quantify eGovernment value and benefits. However, this will lead to issues concerning quantifying and analysing eGovernment value and is a major challenge.

The empirical work indicated that the e-Government implementations in each case study had changed internal working practices. However, these changes have not been evaluated. It is therefore, unclear whether the changes in working practices had led to any improvement or had a detrimental effect on efficiency and effectiveness. This is a issue in any performance assessment exercise.

The case study organisations also recognised that there was difficulty between quantifying evaluation metrics or estimates, and any subsequent analysis. There was also disagreement surrounding which metrics to use. Clearly, this is an issue for external audit bodies charged with assessing public sector performance. One interviewee commented 'It is likely that our Council will be scored low on this issue as we have not undertaken any eGovernment evaluation'. This was a major issue in the public sector organisations and is also a major challenge.

\subsection{Theme Four - Practitioner Concerns}

Practitioner concerns include the important issues in the case study organisations in relation to e-Government evaluation. Practitioners were concerned that responsibility for e-Government evaluation was unclear. Service managers and internal e-Government users need to understand e-Government ownership. Another important issue, as one interviewee commented, was 'how to gauge stakeholder perception of e-government'. It was unclear how successful stakeholders, especially external stakeholders perceive e-Government deployment in the respective councils. There was concern regarding the difficulty in assessing e-Government impact. Often senior management want a financial return from initiatives with a significant ICT element, such as eGovernment. However, this is difficult to demonstrate as noted by Bannister [2]. Practitioners were concerned about the lack of recognition with regards to eGovernment evaluation and that evaluation is an underdeveloped and an under-managed area.

The public sector must be committed to continuous service improvement and e-Government can assist in this area. However, e-Government should be evaluated to gauge the impact on service delivery performance and improvement. Practitioners were concerned that this was not being undertaken. 


\section{5. e-Government Classification and Evaluation Framework}

The findings and analysis of the four main emergent themes have been classified and mapped onto table 1 and figure 1 below. Table 1 culminates a broad classification of factors surrounding the development of an eGovernment infrastructure and then correlates concerns to each classification. Then, a normative reference source is provided. Figure 1 thenceforth shows a classification and definition of those quantitative and qualitative issues as related to the factors highlighted in Table 1 . The figure shows a grouping of the pertinent issues found across the case studies. This diagram ultimately relates notions of Decision-Making, Evaluation, Performance Assessment and Practitioner Concerns to quantitative factors of Responsibility, Sponsorship, Evaluation and Prioritisation; and to qualitative factors of Ownership, Adoption, Evaluation and Social Factors. Based within the context of the extant literature on IS evaluation as described earlier, it should come as no surprise that Evaluation should encompass both explicit (direct) and tacit (indirect) assessments of the investment to be appraised, as discussed at length by Irani [8] and Irani and Love [9]. Therefore the diagram in Figure 1 attempts to show the delicate balance between a systematic as well as a systemic view of e-Government implementation initiatives.

\begin{tabular}{|c|c|c|}
\hline Classification & Extrapolation of Concerns & References \\
\hline $\begin{array}{l}\text { Decision } \\
\text { Making }\end{array}$ & $\begin{array}{l}\text { - Decision making is often delegated to middle management - lack of } \\
\text { senior buy-in. } \\
\text { - Unsophisticated use of techniques. } \\
\text { - Based on Common sense. } \\
\text { - Opportunist tactics to achieve subjective outcomes. }\end{array}$ & $\begin{array}{l}\text { Jones et al., [11] } \\
\text { Taylor [21] } \\
\text { Bannister [2] } \\
\text { Introna [5] }\end{array}$ \\
\hline $\begin{array}{l}\text { Evaluation } \\
\text { Methods }\end{array}$ & $\begin{array}{l}\text { - } \text { Motivated by value. } \\
\text { - Avoidance of formal methods. } \\
\text { - Scepticism by management to formal methods. } \\
\text { - } \text { Focus on power and persuasion. } \\
\text { - } \text { Appraisal used as justification mechanism not an evaluation process. } \\
\text { Repository. }\end{array}$ & $\begin{array}{l}\text { Jones et al., [11] } \\
\text { Irani et al., [8] } \\
\text { Sharif et al., [19] } \\
\text { Irani and Love [9] } \\
\text { Smithson and Hirschheim } \\
\text { [20] }\end{array}$ \\
\hline $\begin{array}{l}\text { Performance } \\
\text { Assessment }\end{array}$ & $\begin{array}{l}\text { - Need to adopt metrics, in an attempt to benchmark and better } \\
\text { quantify e-Government value and benefits. } \\
\text { - Comprehensive Performance Assessment (CPA), undertaken by } \\
\text { external Government Auditors. } \\
\text { - Conflict between quantifying estimates and the subsequent analysis. } \\
\text { - Disagreement surrounding which metrics to use. }\end{array}$ & $\begin{array}{l}\text { Local Government Act } \\
{[14]} \\
\text { Walsham [23] } \\
\text { Willcocks and Lester [26] }\end{array}$ \\
\hline $\begin{array}{l}\text { Practitioner } \\
\text { Concerns }\end{array}$ & $\begin{array}{l}\text { - The need for e-Government ownership. } \\
\text { - How to gauge stakeholder perception. } \\
\text { - Difficulty in assessing e-Government impact. } \\
\text { - Often senior management want a financial return from ICT. } \\
\text { - Lack of recognition that evaluation is an under-developed and an } \\
\text { under-managed area. }\end{array}$ & $\begin{array}{l}\text { National Assembly for } \\
\text { Wales, [ 16] }\end{array}$ \\
\hline
\end{tabular}

Table 1: Classification of Concerns Surrounding e-Government Provision 


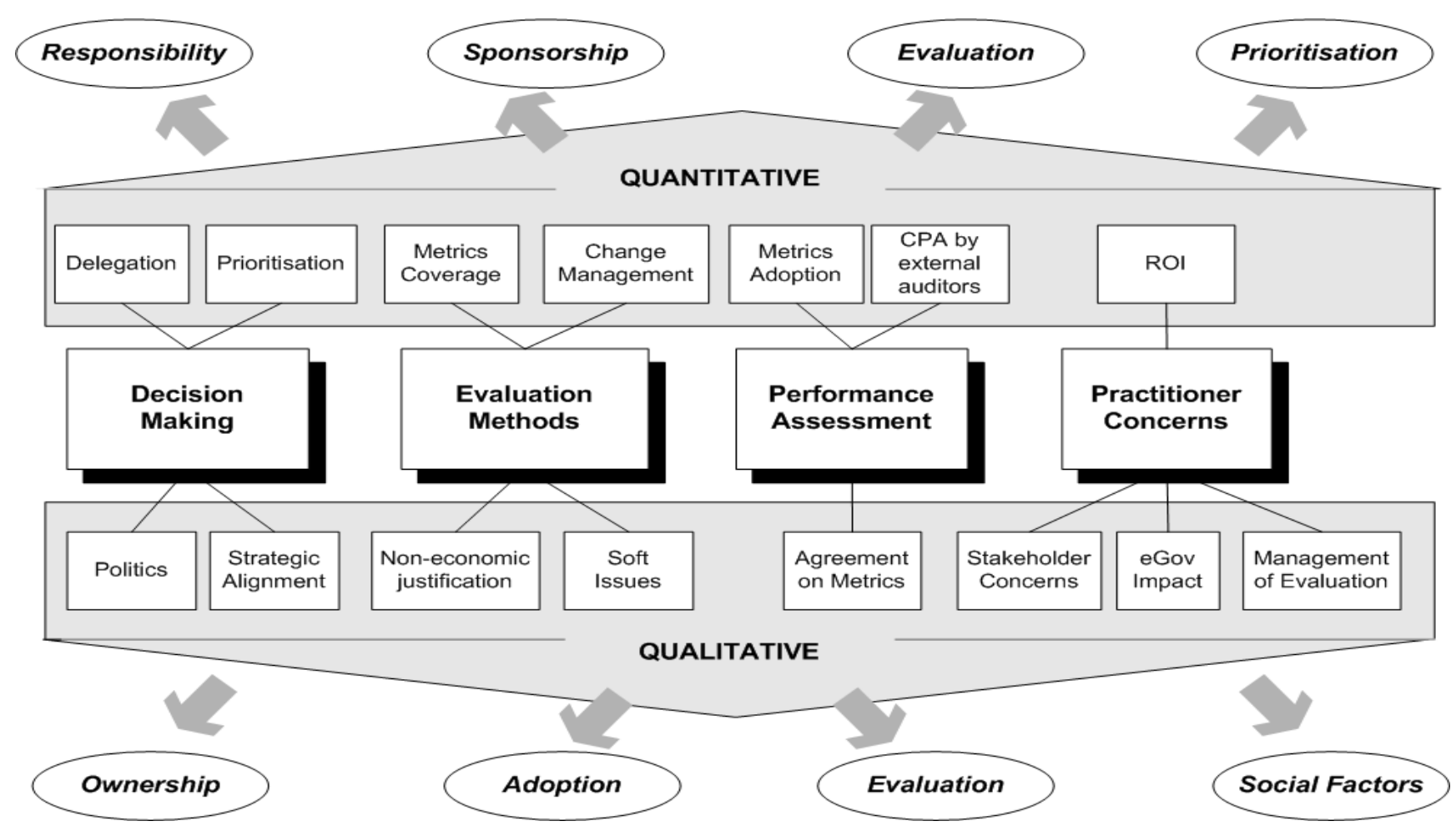

Figure 1: Quantitative and Qualitative issues mapped to observed concerns across three e-Government cases

The authors tentatively suggest that the above table 1 and figure 1 could be usefully deployed as a framework for aiding e-Government evaluation.

\section{Lessons learnt}

Arising from the discussion and analysis of the four main emergent themes, lessons learnt have been elicited to help inform theory and practice. The lessons learnt that are proposed for e-Government evaluation have been elicited from both the literature and by drawing on the three case study analysis undertaken during the empirical work. These lessons have been developed by the authors to help improve e-Government evaluation practice and are presented, as follows:

1. Senior executives should engage with the eGovernment agenda and e-Government evaluation to improve investment decision-making and governance.

2. Organisations should define e-Government ownership to clarify responsibility.

3. Organisations should overcome resistance and ensure that all departments are fully committed to e-Government to obtain maximum exploitation.
4. Organisations should define who is responsible for e-Government evaluation to clarify responsibility.

5. Organisations should undertake e-Government evaluation to understand the impact of eGovernment.

6. Organisations should include soft, social and organisational aspects in any e-Government evaluation model to improve the understanding of e-Government impact.

7. Organisations should prioritise and adequately resource e-Government evaluation to ensure it is undertaken correctly and professionally.

The authors propose to develop these further, together with the proposed tentative e-Government evaluation framework.

\section{Conclusions}

In this paper the authors have presented the findings from three interpretive case studies which have attempted to provide context to the exploration e-Government deployment and adoption issues. The paper has underlined the importance of understanding the complexity and paucity relating to e-Government; taking into account relevant implicit stakeholder effects of 
organisational and individual ownership, accountability and linkage of visibility of such initiatives. Of prime concern is the need to understand and realise the benefits that can be gained from enabling government legislation, processes and systems outwards towards citizen groups not merely doing so for the sake of technology change. The authors believe a consistency in determining and engendering organisational change within and throughout local government authorities and bodies, ultimately drives the adoption of e-Government. This was further shown in terms of a diagrammatic representation of Decision-making, Evaluation Methods, Performance Assessment and Practitioner Concerns factors, broken down into quantitative and qualitative issues. The authors therefore also suggest that the canvassing of stakeholder opinion with regards to the ICT embodiment of organisational processes, is key to e-Government initiative adoption and which provides the basis for accurate and relevant benchmarking of e-Government success metric data. This once again underlines the fine balance between the inclusion of social and non-social factors which combined together, form the antecedents of success and / or failure of such an ICT-based approach. As such, the lessons learnt in analysing the given case studies and the tentative e-Government evaluation framework suggested from within the given initiatives presented in this paper, aims to help improve evaluation practice within this milieu. e-Government evaluation is an under developed area and senior executives need to engage more and commission e-Government evaluation to improve evaluation practice.

\section{Acknowledgements}

The authors acknowledge the support from the Information Systems Evaluation and Integration Group (ISEing) which supported part of this work. ISEing was established at Brunel University Department of Information Systems and Computing, in December 2000, under a research grant from the UK Engineering and Physical Sciences Research Council (EPSRC: GR/R08025/01). Financial support to present this paper will come from the EPSRC funded 'e-Government Integration and Systems Evaluation (e-GISE)'. EPSRC Ref: [GR/T27020/01].

\section{References}

1. Ballantine, J. A., and Stray, S. J., "Information Systems and Other Capital Investments: Evaluation Practices Compared", Logistics and Information Management, 12(1-2), 1999, 78-93.

2. Bannister, F., "Dismantling the Silos: Extracting New Value from IT Investments in Public Administration", Information Systems Journal, 11(1), 2001, 65-84.
3. Fountain, Jane. "Prospects for Improving the Regulatory Process Using E-Rulemaking." Communications of the ACM 46.1 (January 2003).

4. Glaser, B. G., and Strauss, A., The Discovery of Grounded Theory: Strategies for Qualitative Research, Aldine, New York, 1967.

5. Hirschheim, R. A., and Smithson, S., "Evaluation of Information Systems: A Critical Assessment". In Beyond the IT Productivity Paradox (Willcocks, L., and Lester, S., Eds.), Wiley, Chichester, 1998.

6. Hughes, J., and Howcroft, D. A., "Grounded Theory: Never Knowingly Understood", Information Systems Review, 4(1), 2002, 181-197.

7. Introna, L., Management, Information and Power, Macmillan, London, 1997.

8. Irani, Z., "Critical evaluation and integration of information systems": Invited Viewpoint. Business Process Management Journal, 8(4), 2002, 314-317.

9. Irani, Z., and Love, P.E.D., "The propagation of technology management taxonomies for evaluating investments in information systems", Journal of Management Information Systems, 17(3), 2001, 161177.

10. Irani, Z., Jones, S., Love, P.E.D, Elliman, T., and Themistocleous, M., "Evaluating Information System Investments in Local Government: Drawing Lessons from Two Welsh Cases", Information Systems Journal, 15: (1), 2005, 61-82.

11. Jones S, Irani Z, Sharif A.M and Themistocleous M. 2006. "E-Government Evaluation: Reflections on two organizational'. Thirty-ninth annual Hawaii international conference on System Science (HICSS39), [CD Proceedings], January 5-7, Island of Kauai, Hawaii, USA.

12. Land, F. F., "IS Evaluation: Recent Trends", Keynote Speech, NUKAIS Information Systems Evaluation Seminar, Priestley Hall, Leeds Metropolitan University, 27th February, 2001.

13. Lefley, F., and Sarkis, J., "Short-termism and the Appraisal of AMT Capital Projects in the US and UK", International Journal of Production Research, 35(2), 1997, 341-355.

14. Local Government Act, Local Government Act for Local Authorities in England and Wales, Central Government Office, London, 1999.

15. Mayring, P., "Qualitative content analysis", Forum: Qualitative Social Research, 1(2), 2000 1-80.

16. National Assembly for Wales, Guidance to Local Authorities on implementing E-government Statements, National Assembly for Wales, Cardiff, UK, 2002.

17. Remenyi, D., Money, A., Sherwood-Smith and Irani, Z., Effective Measurement and Management of IT Costs and Benefits, Butterworth-Heinemann, Oxford, 2000.

18. Serafeimidis, V., and Smithson, S., "Information Systems Evaluation in Practice: a Case Study of Organisational Change", Journal of Information Technology, 15(2), 2000, 93-105. 
19. Sharif A.M, Irani Z, and Love P.E.D 2005 “ Integration ERP using EAI: A Model for Post-hoc Evaluation European Journal of Information Systems, 14(2): 162-174.

20. Smithson, S., and Hirschheim, R. A., "Analysing Information Systems Evaluation: Another Look at an Old Problem", European Journal of Information Systems, 7(3), 1998, 158-174.

21. Taylor, F. W. "Scientific Management". In Pugh, D. S. (Ed.), Organisation Theory: Selected Readings, Penguin, London, 1990, 275-295.

22. Urquhart, C. "An Encounter with Grounded Theory: Tackling the Practical and Philosophical Issues", In Qualitative Research in Information Systems: Issues and Trends (Trauth, E., Ed), Idea Group Publishing, London, 2001
23. Walsham G., Interpreting Information Systems in Organizations, John Wiley \& Sons, Chichester, 1993.

24. Walsham, G., "Interpretive Case Studies in ICT Research: Nature and Method", European Journal of Information Systems 4(2), 1995, 74-81.

25. Walsham, G., Interpretive Evaluation Design for Information Systems. In Beyond the IT Productivity Paradox (Willcocks, L. and Lester, S., Eds.), Wiley, Chichester, 1998.

26. Willcocks, L., and Lester, S., "Information Technology: Transformer or Sink Hole", In Beyond the IT Productivity Paradox (Willcocks, L., and Lester, S., Eds.), Wiley, Chichester, 1998.

27. Yin, R.K., Case study research: Design and Methods $2^{\text {nd }}$ Edition, Sage Publications, Thousand Oaks, CA, 199 